\title{
Ergonomic Comparison of a Sit-Stand Workstation With a Traditional Workstation in Visual Display Unit Work
}

\author{
Nina Nevala ${ }^{*}, 1,2$ and Dong-Shik Choi ${ }^{1,3}$ \\ ${ }^{1}$ Finnish Institute of Occupational Health, Ergonomics and Usability, Topeliuksenkatu 41 a A, FI-00250 Helsinki, \\ Finland \\ ${ }^{2}$ University of Jyväskylä, Gerontology Research Centre and Department of Health Sciences, Box 35, FI-40014 \\ University of Jyväskylä, Finland \\ ${ }^{3}$ Korea Occupational Safety and Health Agency, Pohang, 790-823, South-Korea
}

\begin{abstract}
Purpose: To compare ergonomics of an electrically adjustable sit-stand workstation with a traditional workstation in video display unit (VDU) work.

Methods: Twelve female workers (aged 27-53 years) participated in this experimental study. Electromyography, wrist postures, subjective assessments, and productivity were used to make the ergonomic comparison.

Results: The muscle activity of the right trapezius $(\mathrm{p}=0.01)$ and left wrist extensors $(\mathrm{p}=0.02)$, extension of the right $(\mathrm{p}=0.05)$ and left $(\mathrm{p}=0.002)$ wrist, and perceived strain of the arms $(\mathrm{p}=0.05)$ were lower and productivity was better $(\mathrm{p}=0.02)$ when the workers used a low-sitting, high-sitting, or standing posture at the sit-stand workstation than when using a low-sitting posture at the traditional workstation. In the whole, the subjects were more satisfied $(\mathrm{p}=0.05)$ with the sit-stand workstation than with the traditional workstation.

Conclusions: Working both in sitting and standing postures was more productive and caused lower strain of the workers' upper limbs than work only in a sitting posture. The electrically adjustable sit-stand workstation offers the possibility to reduce the sedentary behavior and inactivity in VDU work.
\end{abstract}

Keywords: Ergonomics, sedentary work, sit-stand workstation, standing, visual display unit.

\section{INTRODUCTION}

Epidemiological evidence suggests that decrease in sedentary behavior is beneficial for health [1]. Objectively measured data show that people spend in USA and Australia on average $7.7 \mathrm{~h} /$ day and $8.1 \mathrm{~h} /$ day in sedentary behavior, respectively [2,3]. Finni et al. [4] have shown that exercise for fitness, regardless of its duration, does not decrease the inactivity time during normal daily life. Further, different counseling interventions have been carried out to decrease sedentary behavior [5].

Sit-stand workstations offer one possibility of decreasing sedentary behavior and varying work postures during work day [6-9]. Workers can select low-sitting, high-sitting, and standing postures according to their needs and tasks and adjust the work station height easily [9, 10]. Ergonomic sitting and standing postures are typically used in the prevention of musculoskeletal disorders such as low-back pain and upper-limb disorders $[6,11,12]$. According to Callaghan and McGill [9], sitting resulted in higher $(\mathrm{p}<0.001)$ low back compressive loads than those experienced by the lumbar spine during standing.

Address correspondence to this author at the Finnish Institute of Occupational Health, Ergonomics and Usability, Topeliuksenkatu 41 a A, FI-00250 Helsinki, Finland; Tel: +358 40 7344166;

E-mail: nina.nevala@ttl.fi
Further, good forearm support has been shown to reduce the musculoskeletal exposure, and discomfort in VDU work [13-16] Dainoff et al. [7] reported about an ergonomic intervention, which included also a use of motorized adjustable workstations in VDU work, that musculoskeletal pain among the VDU workers reduced significantly. According to Schofield et al. [17] standing and typing produced an average of $13 \%$ higher energy expenditure than sitting and typing did, and it can therefore reduce the risk of weight gain. According to the review of Reid et al. [18] both prolonged standing and sitting can cause discomfort of the lower extremities. Leg swelling is also more typical during long-lasting standing [19].

The ergonomics of sit-stand workstations have been evaluated earlier for VDU work $[6,9,20]$. According to Wilks et al. [9], 60\% of the workers used the sit-stand function of the table once monthly or less, and the frequency was even lower among the older participants. Also pain experienced during the past year and education on the use of the worktable increased the use of the adjustability function [8]. According to Straker et al. [6], use of sit-stand desks was associated with better sedentary behavior in call center workers, however ergonomics awareness did not enhance the effect. In other occupations, use of an electrically adjustable worktable in microscope work decreased the muscle strain of neck and upper limbs among laboratory workers [21]. Jung 
[22] and Koskelo et al. [23] showed that use of adjustable school furniture decreased muscular strain, developed general posture, and increased learning results of the students.

Electrically adjustable workstations have been used as workplace accommodations for workers with long-standing diseases or permanent physical disabilities [24]. Shen et al. [25] showed, that the cutout surface of the worktable provided forearm support in addition to improving writing performance among students with physical disabilities. New reclining/supine computer workstations have also been developed for workers with chronic low back pain who cannot work in sitting position [26].

The use of an adjustable workstation decrease musculoskeletal exposure of workers [27] and enhance work productivity [9, 10, 20]. Hasegawa et al. [28] reported the effects of a sit-stand schedule on a light repetitive task and concluded that a "change of posture" is useful to reduce the monotonous feelings of fatigue in a short-term, light, repetitive task.

The aim of this study was to compare ergonomics of an electrically adjustable sit-stand workstation with a traditional workstation in VDU work.

\section{MATERIALS AND METHODS}

\section{Subjects}

The subjects were 12 healthy female workers (aged 2753 years) from one office (Table 1). They were all righthanded and used a traditional mouse and keyboard. They were accustomed to work at both an electrically adjustable sit-stand workstation and a traditional workstation. During their normal work, the participants adjusted the height of their sit-stand workstation an average of $6(0-20)$ times a week, mainly due to perceived tiredness and strain. The volunteer subjects were individually informed of the study, and they gave their written consent to participate before the study began. Before the measurements, the subjects were assigned to two study groups of six participants each, the groups having a different order for the use of the workstations.

Table 1. Background Factors of the Participants $(n=12)$. The values are Means, Standard Deviations (SD), and Ranges

\begin{tabular}{|l|c|c|c|}
\hline \multicolumn{1}{|c|}{ Variable } & Mean & SD & Range \\
\hline \hline Age (years) & 38 & 9 & $27-53$ \\
\hline Height (cm) & 169 & 6 & $158-180$ \\
\hline Weight (kg) & 64 & 8 & $50-76$ \\
\hline Experience in VDU work (years) & 9 & 4 & $3-15$ \\
\hline $\begin{array}{l}\text { Experience in using a sit-stand } \\
\text { workstation (months) }\end{array}$ & 14 & 13 & $2-48$ \\
\hline
\end{tabular}

\section{Study Design}

This study was a comparative experiment. The measurements of each subject were carried out during one day in a simulated situation (Fig. 1). During the study the subjects worked at both workstations (sit-stand workstation, traditional workstation) for 42 minute (Fig. 2). They worked at the sit-stand workstation in a low-sitting position (LS) for 14 minutes, in a high-sitting position (HS) for 14 minutes, and in a standing position (ST) for 14 minutes. At the traditional workstation they worked for 42 minutes in a lowsitting position. At both workstations, the same standardized mouse and typing tasks were conducted during the measurements, and the tasks were changed every 7 minutes. During the measurements, all 12 subjects worked for 42 minute at both work stations, six subjects first worked at the sit-stand workstation, and six first at the traditional workstation.

\section{Methods}

The sit-stand workstation was evaluated with the use of musculoskeletal exposure measurements (electromyography, wrist angles), subjective evaluations (perceived musculoskeletal strain, and satisfaction), and productivity (a mouse and a typing task).

Electromyography (EMG) was recorded from four muscles of the upper body bilaterally ( $\mathrm{m}$. erector spinae, $\mathrm{m}$. trapezius pars descendes, m. extensor digitorum communis, $\mathrm{m}$. erector spinae trunci) with a portable ME3000P device with a video option (Mega Electronics, Finland) [29]. The EMG was recorded using the averaged mode, a sampling frequency of $1000 \mathrm{~Hz}$, a time interval of 0.1 seconds, and a bipolar setting of disposable surface electrodes (M-OO-S, Medicotest, Denmark). The positions of the electrodes were defined according to the recommendations of Zipp [30]. The maximal muscular activity of the three muscles was registered during their maximal isometric voluntary contractions (MVC) and standardized as the percentage of the MVC (\%MVC). The studied worktasks were videorecorded with a Panasonic S-VHS-C video camera. The EMG data were transferred via an optic link to a computer. The analyses and calculations were performed by attached software.

Wrist extension/flexion and ulnar/radial deviation were measured using a two-channel electronic goniometer (Type XM110, Penny \& Giles Blackwood Ltd, UK) attached to the wrists of the worker with skin adhesive tape [31]. The output from the goniometers was sampled with a portable device (ME3000P, Mega Electronics Ltd, Finland) at a frequency of $250 \mathrm{~Hz}$, using the averaged mode and a time constant of 0.1 seconds, and stored on a computer for analysis with ME3000P software.

Visual analogue scales (VAS) were used to determine the musculoskeletal strain, and satisfaction with the sit-stand and the traditional workstation [32]. The workers rated their perceived strain on modified VAS, the result of each scale being reported in millimeters (range 0-100 $\mathrm{mm}$ with end points of " 0 not at all strainful - 100 very strainful"). Satisfaction with the workstation was asked with the question "How satisfied you are with the workstation (VAS, "0 not at all satisfied - 100 very satisfied")?

Productivity was evaluated using the number of right strokes per 42 minutes during the standardized mouse and typing tasks. In the mouse task (Fig. 3), developed for this study, the participants used the mouse to delete the middle digit from each item in a special order $(111>11, \mathrm{j} 0 \mathrm{j}>\mathrm{jj}$, 

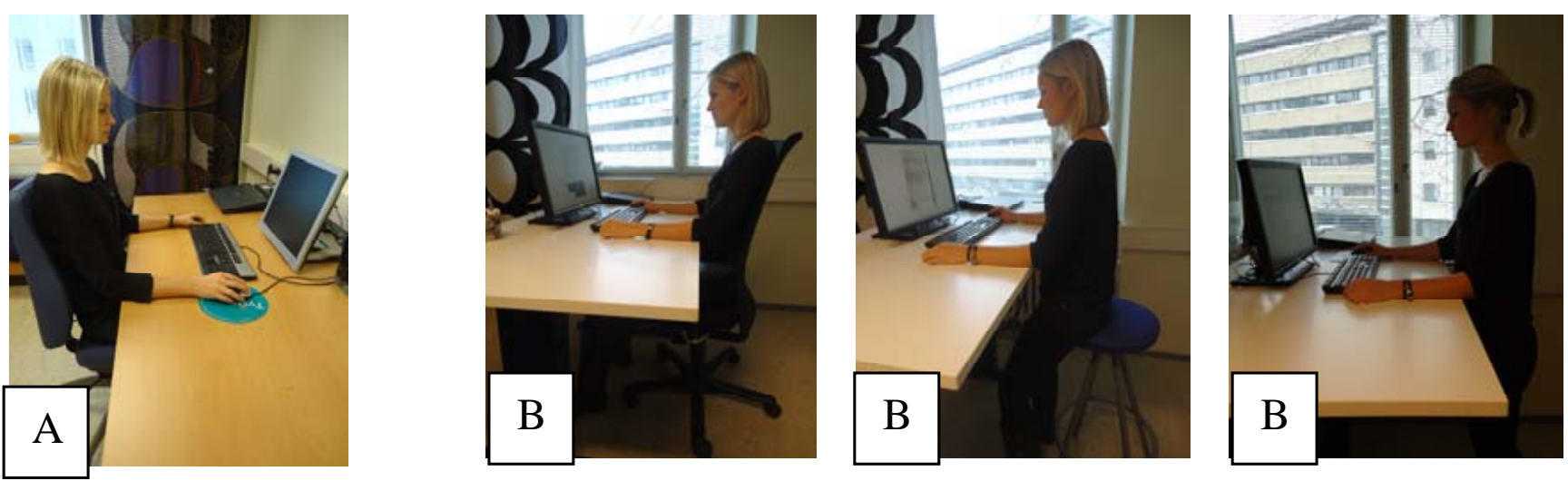

Fig. (1). The traditional workstation (A), and the electrically adjustable sit-stand workstation (B).

\begin{tabular}{|c|c|c|c|c|c|c|c|c|c|c|c|c|c|c|c|c|}
\hline \multirow{2}{*}{$\begin{array}{l}\text { Task } \\
\text { (min) }\end{array}$} & & $M$ & $\mathrm{~T}$ & $M$ & $T$ & $M$ & $T$ & & & $M$ & $\mathrm{~T}$ & $M$ & $T$ & $M$ & $\mathrm{~T}$ & \\
\hline & & 7 & 7 & 7 & 7 & 7 & 7 & & & 7 & 7 & 7 & 7 & 7 & 7 & \\
\hline \multirow{3}{*}{$\begin{array}{l}\text { Posture } \\
\text { (min) }\end{array}$} & & & & & & & & & & & & & & & & \\
\hline & & LS & & & & & & & & LS & & HS & & ST & & \\
\hline & & 42 & & & & & & & & 14 & & 14 & & 14 & & \\
\hline \multirow{2}{*}{$\begin{array}{l}\text { Function } \\
\text { (min) }\end{array}$} & 11 & T1 & & & & & & Q1 & 12 & T2 & & & & & & Q2 \\
\hline & 8 & 42 & & & & & & 10 & 8 & 42 & & & & & & 10 \\
\hline
\end{tabular}

Fig. (2). The test schedule of each participant $(\mathrm{n}=12)(\mathrm{I} 1=$ Information $1, \mathrm{~T} 1=$ Test $1, \mathrm{Q} 1=$ Questionnaire $1, \mathrm{I} 2=\mathrm{Information} 2$, T2 $=$ Test 2, Q2 = Questionnaire 2, LS = low-sitting, HS = high-sitting, ST = standing, M = mouse task, T = typing). Function shows the phases of the experiment. The three scales (Task, Posture, Function) have time in common.

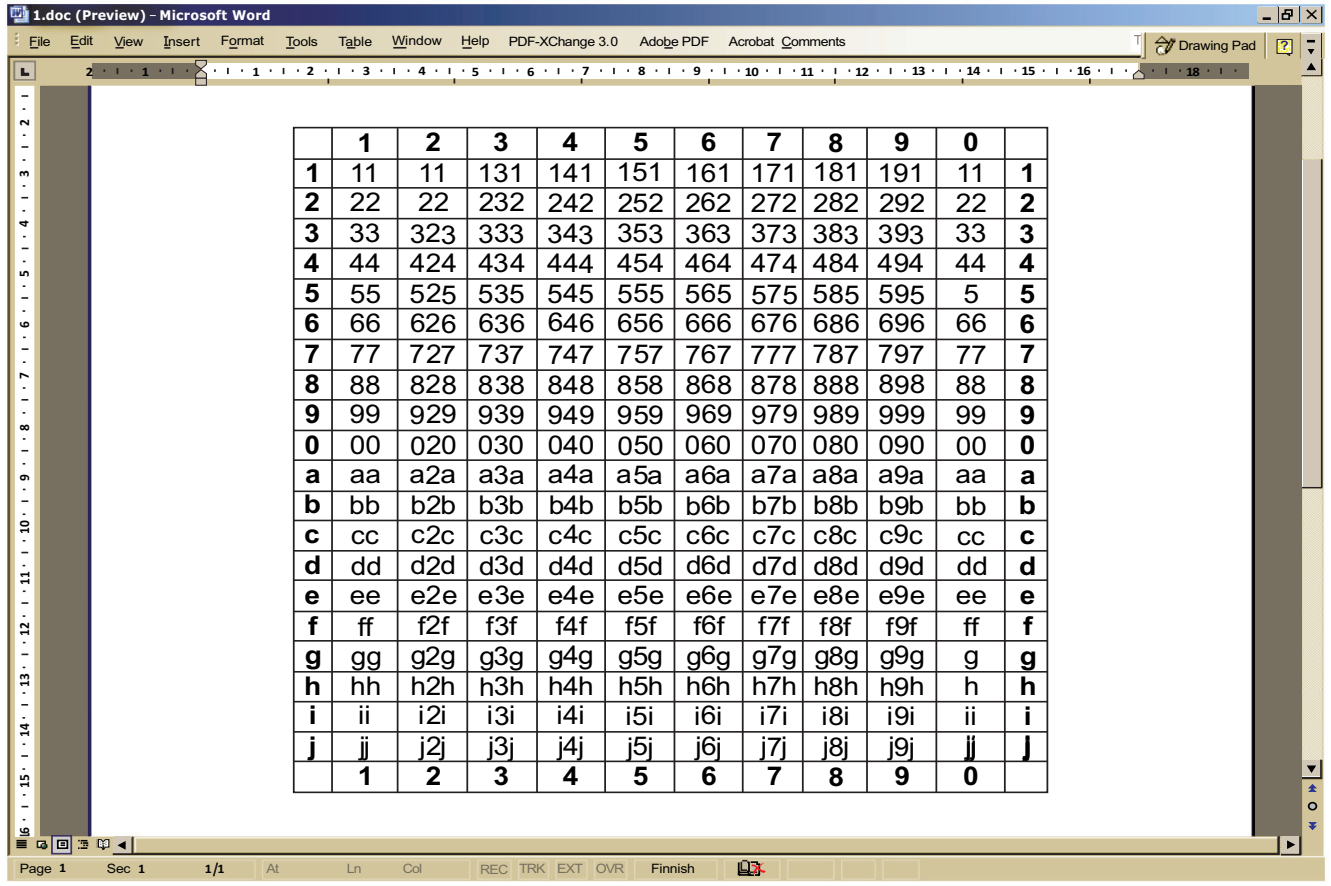

Fig. (3). The standardized mouse task in which the middle digit was deleted from each cell in systematic order $(111>11, \mathrm{j} 0 \mathrm{j}>\mathrm{jj}, 212>22$, i0i > ii, etc.).

$212>22$, i0i>ii, etc.) In the typing task, the same Finnish text was used to determine the writing speed [33].
The results were analyzed using the GLM procedure of SAS (Statistical Analysis System v6.12). The means, standard deviations, and ranges were used for the descriptive 
evaluation. The independent variable in all of the analyses was the workstation model (sit-stand workstation, traditional workstation). The dependent variables were the muscular activity of the three muscles, the angle of the wrists, the perceived musculoskeletal strain in different body parts, satisfaction, and the number of correct strokes. The differences between the sit-stand and traditional workstations and the testing order were tested using a paired $t$-test. The differences were considered statistically significant if $\mathrm{p}<0.05$.

\section{RESULTS}

The test order of the workstation (sit-stand, traditional) had no statistically significant effect on the outcome variables. There were statistically significant differences in the \% MVC values when the workstations are compared. The muscle activity of the right trapezius $(p=0.01)$ and the left extensor digitorum communis $(p=0.02)$ were lower when the participants worked at the sit-stand workstation than when they worked at the traditional workstation (Table 2). There were no statistically significant differences in the activity of the other muscles when the subjects worked at these two workstations.

The extension of both wrists was significantly lower when the subjects worked at the sit-stand workstation compared to the traditional workstation (Table 3). No differences were found in wrist deviation of the subjects when the two workstations were compared.

There was a statistically significant difference in perceived musculoskeletal strain of two body parts between the workstations. The subjects perceived lower $(\mathrm{p}=0.05)$ strain in their arms when they worked in different postures (low-sitting, high-sitting, standing) at the electrically adjustable sit-stand workstation than in work at the traditional workstation (Table 4). However, work at the sitstand workstation caused higher $(\mathrm{p}=0.01)$ perceived strain in lower limbs than work in low-sitting posture at the traditional workstation. No statistical differences were found in other body parts between the workstations. In the whole, the participants were more satisfied $(\mathrm{p}=0.05)$ with the sitstand workstation than with the traditional workstation.

Productivity measured with the correct strokes per 42 minutes (mouse task and typing task) was $10 \%$ better $(p=0.02)$ at the adjustable sit-stand workstation than at the traditional workstation.

\section{DISCUSSION}

With increasing VDU work in most jobs, sitting has become a main part of most working environments. Accordingly, any activity that decreases inactivity time, like sitting, may benefit health $[1-5,13]$.

This study showed that work productivity and satisfaction were better and musculoskeletal exposure was lower during VDU work alternately in low-sitting, highsitting, and standing positions than during the work in the sitting position. Especially the muscular strain and perceived strain in the upper limbs was lower at the sit-stand workstation.
Table 2. Mean Muscle Activity (Electromyography, EMG, \%MVC) in Four Muscle Groups Bilaterally During the Standardized VDU Worktasks of the Participants $(n=12)$ at the Electrically Adjustable Sit-Stand Workstation (in Low-Sitting, High-Sitting and Standing Positions) and at the Traditional Workstation (in Low-Sitting Position)

\begin{tabular}{|c|c|c|c|c|}
\hline Body Part/Muscle & $\begin{array}{c}\text { Body } \\
\text { Side }\end{array}$ & $\begin{array}{c}\text { Sit-Stand } \\
\text { Workstation }\end{array}$ & $\begin{array}{c}\text { Traditional } \\
\text { Workstation }\end{array}$ & p \\
\hline \hline \multirow{2}{*}{$\begin{array}{c}\text { Neck/Musculus } \\
\text { Erector Spinae }\end{array}$} & Right & 5.5 & 5.2 & $\mathrm{~ns}$ \\
\cline { 2 - 5 } & Left & 5.3 & 4.8 & $\mathrm{~ns}$ \\
\hline $\begin{array}{c}\text { Shoulder/Musculus } \\
\text { Trapezius }\end{array}$ & Right & 7.0 & 9.7 & 0.01 \\
\cline { 2 - 5 } & Left & 5.9 & 5.2 & $\mathrm{~ns}$ \\
\hline $\begin{array}{c}\text { Arm/Musculus Extensor } \\
\text { Digitorum Communis }\end{array}$ & Right & 10.1 & 10.4 & $\mathrm{~ns}$ \\
\cline { 2 - 5 } & Left & 9.1 & 9.8 & 0.02 \\
\hline $\begin{array}{c}\text { Back/Musculus } \\
\text { Erector Spinae Trunci }\end{array}$ & Right & 2.1 & 1.2 & $\mathrm{~ns}$ \\
\cline { 2 - 5 } & Left & 2.0 & 1.2 & $\mathrm{~ns}$ \\
\hline
\end{tabular}

Table 3. Mean Wrist Extension and Ulnar Deviation (Degree) of the Participants $(n=12)$ During the Standardized VDU Worktasks at the Electrically Adjustable SitStand Workstation (in Low-Sitting, High-Sitting and Standing Positions) and at the Traditional Workstation (in Sitting Position)

\begin{tabular}{|c|c|c|c|c|}
\hline $\begin{array}{c}\text { Wrist } \\
\text { Posture }\end{array}$ & $\begin{array}{c}\text { Body } \\
\text { Side }\end{array}$ & $\begin{array}{c}\text { Sit-Stand } \\
\text { Workstation }\end{array}$ & $\begin{array}{c}\text { Traditional } \\
\text { Workstation }\end{array}$ & p \\
\hline \hline \multirow{2}{*}{ Extension } & Right & 22 & 24 & 0.05 \\
\cline { 2 - 5 } & Left & 18 & 21 & 0.002 \\
\hline \multirow{2}{*}{ Deviation } & Right & 10 & 11 & $\mathrm{~ns}$ \\
\cline { 2 - 5 } & Left & 13 & 14 & $\mathrm{~ns}$ \\
\hline
\end{tabular}

Table 4. Mean Perceived Musculoskeletal Strain (Visual Analogue Scales, VAS, mm, $0=$ Not at all Strainful 100 Very Strainful) for Different Body Parts of the Participants $(n=12)$ After the Standardized VDU Worktasks at the Sit-Stand Workstation (LowSitting, High-Sitting and Standing Positions) and at the Traditional Workstation (Low-Sitting Position).

\begin{tabular}{|c|c|c|c|}
\hline $\begin{array}{c}\text { Body } \\
\text { Part }\end{array}$ & $\begin{array}{c}\text { Sit-Stand } \\
\text { Workstation }\end{array}$ & $\begin{array}{c}\text { Traditional } \\
\text { Workstation }\end{array}$ & p \\
\hline \hline Neck-Shoulder & 27 & 34 & $\mathrm{~ns}$ \\
\hline Upper limbs & 33 & 42 & 0.05 \\
\hline Back & 30 & 32 & $\mathrm{~ns}$ \\
\hline Lower limbs & 41 & 26 & 0.01 \\
\hline
\end{tabular}

The productivity of the participants was $10 \%$ better when the same tasks were done at the sit-stand workstation than it was at the traditional workstation. This finding is in line with 
the results of previous studies $[9,20]$. However, in this study the productivity was measured using a quantitative method developed for this study in co-operation with the experts of technical ergonomics and psychology.

The participants were more satisfied $(p=0.05)$ with the sit-stand workstation than with the traditional workstation. The adjustability offers the possibility to have an influence on own work behavior. The better satisfaction can also be due to the lower exposure and strain of upper limbs and possibility to vary the work postures according to the task and perceived strain.

The subjects perceived lower $(p=0.05)$ strain in their arms and higher $(\mathrm{p}=0.01)$ strain in their lower limbs when they worked in different postures (low-sitting, high-sitting, standing) at the sit-stand workstation. The lower strain in the arms is obviously due to the lower static exposure of the arms. The electrically adjustable table offers possibilities to adjust the table height so that it is good for supporting the arms in different tasks. Resting the arms on the table surface has been found to be associated with a reduced risk of neck and shoulder pain and lower discomfort [13-16]. Possibility to support arms also increases the function of arms among persons with disabilities [25].

The subjects perceived higher strain in the lower limbs when they worked at the sit-stand workstation although they changed their working posture every 14 minutes and they had no overweight. This result is in accordance with the review of Reid et al. [18]. This shows that moving and dynamic movements are important both in standing and sitting postures $[12,18]$. It would be important to develop new solutions to do activities in standing positions during VDU work.

The extension of both wrists was significantly lower when the subjects worked at the sit-stand workstation. This is an important result, because the bent postures of the wrists are main causation of carpal tunnel syndrome [7]. However, no differences were found in wrist deviation when the two workstations were compared. The suitable height of the working surface enabled the participants to keep their wrists in a more neutral position. This finding agrees with the results elicited during the use of arm rests [13]. It is obvious, that too low working surface in VDU work will cause greater extension of the wrists.

This study evaluated an electrically adjustable sit-stand workstation by comparing it with the traditional workstation. The study was planned in cooperation with researchers, workstation manufacturers, and experienced office workers in a participative way. The evaluation was made using the quantitative (EMG, wrist angle, VAS, productivity) methods. The 42-minute VDU task duration was chosen because it seemed to correspond to an average continuous VDU task in an actual work situation. All 12 subjects worked for 42 minute at both work stations and they had a pause between the workstations. The participants represented typical female workers in Finland and they were accustomed to using both of the tested workstations.

Sit-stand workstation offers the possibility to reduce the sedentary behavior and inactivity during the work day. These possibilities should be used when new office environments are designed or old offices are redesigned. Easily adjustable workstations are especially important in open offices where the same workstations are shared by several workers. However, the correct use of technical accessories such as adjustable workstations requires that all of the workers involved be well educated and systematically motivated. Sitstand workstations can be used in the primary prevention when working comfort will be increased. In secondary prevention, the possibility to work also in high-sitting and standing positions is important, for example, for workers with acute back pain. In tertiary prevention, electrically adjustable workstations are proper workplace accommodations among persons with permanent disabilities [24].

\section{CONCLUSIONS}

Working both in sitting and standing postures was more productive and caused lower strain of the workers' upper limbs than work only in a sitting posture. The electrically adjustable sit-stand workstation offers the possibility to reduce the sedentary behavior and inactivity in VDU work.

\section{CONFLICT OF INTEREST}

The authors confirm that this article content has no conflict of interest.

\section{ACKNOWLEDGEMENTS}

The authors wish to thank Kari Ojanen, M.Sc (techc.) and Alpo Kulmala, psychologist, for developing the mouse task, and Maria Hirvonen, Special Expert, for her help with the statistical analyses. The authors would also like to thank the volunteer workers who made this project possible.

\section{REFERENCES}

[1] Patel AV, Bernstein L, Deka A, et al. Leisure time spent sitting in relation to total mortality in a prospective cohort of US adults. Am J Epidemiol 2010; 172: 419-29.

[2] Healy GN, Wijndaele K, Dunstan DW, et al. Objectively measured sedentary time, physical activity, and metabolic risk: the Australian Diabetes, Obesity and Lifestyle Study (AusDiab). Diabetes Care 2008; 31: 369-71.

[3] Matthews CE, Chen KY, Freedson PS, et al. Amount of time spent in sedentary behaviors in the United States, 2003-2004. Am J Epidemiol 2008; 167: 875-81.

[4] Finni T, Sääkslahti A, Laukkanen A, Pesola A, Sipilä S. A family based tailored counselling to increase non-exercise physical activity in adults with a sedentary job and physical activity in their young children: design and methods of a year-long randomized controlled trial. BMC Public Health 2011; 11: 944.

[5] Finni T, Haakana P, Pesola AJ, Pullinen T. Exercise for fitness does not decrease the muscular inactivity time during normal daily life. Scand J Med Sci Sports 2012. [Epub ahead of print].

[6] Straker L, Abbott RA, Heiden M, Mathiassen SE, Toomingas A. Sit-stand desks in call centres: Associations of use and ergonomics awareness with sedentary behavior. Appl Ergon 2013; 44(4): 511668.

[7] Matias AC, Salvendy G, Kuczek T. Predictive models of carpal tunnel syndrome causation among VDT operators. Ergonomics 1998; 41: 213-26.

[8] Dainoff MJ, Cohen BGF, Dainoff MH. The effect of an ergonomic intervention on musculoskeletal, psychosocial and visual strain of VDT data entry work: The United States part of the international study. Int J Occup Saf Ergon 2005; 11: 49-63.

[9] Wilks S, Mortimer M, Nylén P. The introduction of sit-stand worktables; aspects of attitudes, compliance and satisfaction. Appl Ergon 2006; 37: 359-65.

[10] Ebara T, Kubo T, Inoue $\mathrm{T}$, et al. Effects of adjustable sit-stand VDT workstations on workers' musculoskeletal discomfort, alertness and performance. Ind Health 2008; 46: 497-505. 
[11] Ketola R, Toivonen R, Häkkänen M, Luukkonen R, Takala E-P, Viikari-Juntura E. Effects of ergonomic intervention in work with video display units. Scand J Work Environ Health 2002; 28: 18-24.

[12] Callaghan JP, McGill SM. Low back joint loading and kinematics during standing and unsupported sitting. Ergonomics 2001; 44: 280-94.

[13] Lintula M, Nevala-Puranen N, Louhevaara V. Effects of Ergorest ${ }^{\circledR}$ arm supports on muscle strain and wrist positions during the use of the mouse and keyboard in work with Visual Display Units: A work site intervention. Int J Occup Safety Ergon (JOSE) 2001; 7: 103-16.

[14] Cook C, Burgess-Limerick R, Papalia S. The effect of upper extremity support on upper extremity posture and muscle activity during keyboard use. Appl Ergon 2004; 35: 285-92.

[15] Rempel DM, Krause N, Goldberg R, Benner D, Hudes M, Goldner GU. A randomised controlled trial evaluating the effects of two workstation interventions on upper body pain and incident musculoskeletal disorders among computer operators. Occup Environ Med 2006; 63: 300-6.

[16] Murphy T, Oliver ML. Evaluation of a dynamic armrest for hydraulic-actuation controller use. Appl Ergon 2011; 42: 692-8.

[17] Schofield G, Kilding A, Freese R, Alison A, White K. Standing up at work: The feasibility of using height adjustable desks to reduce sedentary behaviour and increase energy expenditure. J Sci Med Sport 2009; 12S: S1-83.

[18] Reid CR, Bush M, Karwowski W, Durrani SK. Occupational postural activity and lower extremity discomfort: A review. Int $\mathbf{J}$ Ind Ergon 2010; 40: 247-56.

[19] Chester MR, Rys MJ, Konz SA. Leg swelling, comfort and fatigue when sitting, standing, and sit/standing. Int J Ind Ergon 2002; 29: 289-96.

[20] Hedge A, Ray EJ. Effects of an electronic height adjustable worksurface on self-assessed musculoskeletal discomfort and productivity among computer workers. Proceedings of the Human Factors and Ergonomics Society, 48th Annual Meeting 2004; pp. 1091-5.

[21] Sillanpää J, Nyberg M, Laippala P. A new table for work with a microscope, a solution to ergonomic problems. Appl Ergon 2003; 34: 621-8.
[22] Jung HS. A prototype of an adjustable table and an adjustable chair for schools. Int J Ind Ergon 2005; 35: 955-69.

[23] Koskelo R, Vuorikari K, Hänninen O. Adjustable school furniture improves students' posture. Ergonomics 2007; 50: 1643-56.

[24] Nevala N, Kalliomäki-Levanto T, Jääskeläinen K, Pekkarinen A, Elo J. Accomodating working conditions of persons with disabilities or long-standing health problems in the open labour market. In: Lindfors J, Savolainen M, Väyrynen S, Eds. Wellbeing and Innovations Through Ergonomics. Proceedings of NES2011. Oulu, Finland: University of Oulu 2011; pp. 330-5.

[25] Shen I, Kang S, Wu C. Comparing the effect of different design of desks with regard to motor accuracy in writing performance of students with cerebral palsy. Appl Ergon 2003; 34: 141-7.

[26] Haynes S. Effects of positioning optimization in an alternative computer workstation for people with and without low back pain Int J Ind Ergon 2009; 39: 719-27.

[27] Nevala N, Ketola R. Birthing support for midwives and mothers ergonomic testing and product development. Ergon Open J 2012; 5: 28-34.

[28] Hasegawa T, Inoue K, Tsutsue O, Kumashiro M. Effects of a sitstand schedule on a light repetitive task. Int J Ind Ergon 2001; 28: 219-24.

[29] Remes A, Rauhala E, Hänninen O. Fully rectified, integrated, band (Frib-) EMG analysis in quantifying muscle activity. Development of a new field equipment. Acta Physiol Scand 1984; 537: 65-70.

[30] Zipp P. Recommendations for the standardization of lead positions in surface electromyography. Eur J Appl Phys Occup Phys 1982; 50: 41-54.

[31] Buchholz B, Wellman H. Practical operation of a biaxial goniometer at the wrist joint. Hum Fact 1997; 39: 119-29.

[32] Price D, McGrath PA, Rafii A, Buckinham B. The validation of visual analogue scale as ratio scale measure for chronic and experimental pain. Pain 1983; 17: 45-56.

[33] Suomalainen P, Korpinen L, Pääkkönen R. A comparison of the usability of a laptop, communicator, and handheld computer. J Usability Stud 2010; 5: 111-23. 